\title{
Automatización de las bases de datos: potencialidades de herramientas básicas para otro periodismo posible
}

\author{
Por Xosé López-García, Carlos Toural-Bran, Xosé Pereira-Fariña y Suzana Barbosa
}

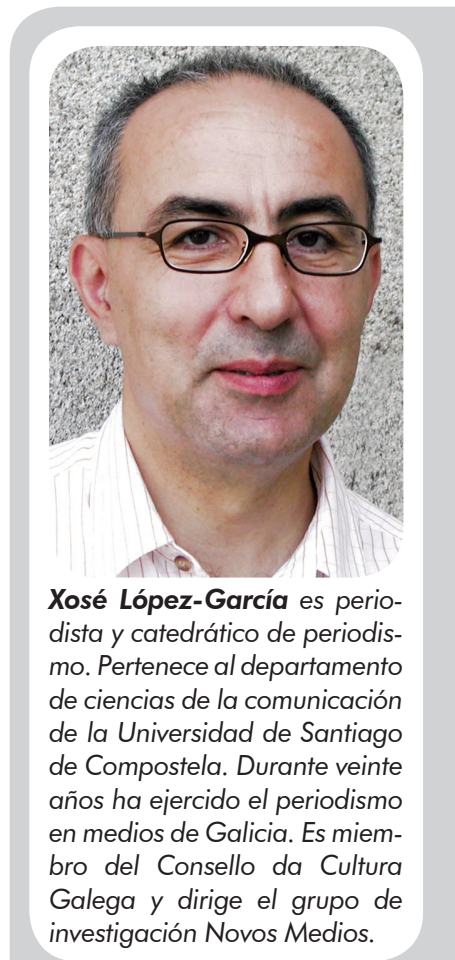

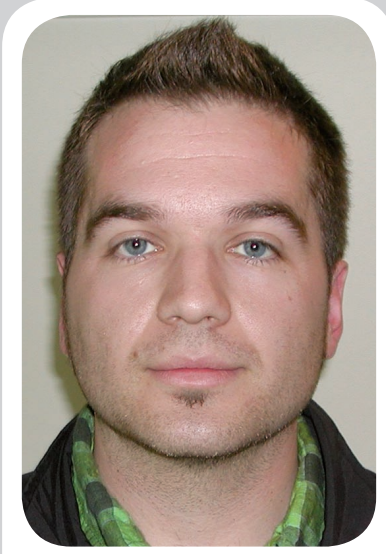

Carlos Toural-Bran es licenciado en periodismo y contratado predoctoral (beca María Barbeito de la Xunta de Galicia) en el departamento de ciencias de la comunicación de la Facultad de Ciencias de la Comunicación de la Universidad de Santiago de Compostela. Es miembro del grupo de investigación Novos Medios.

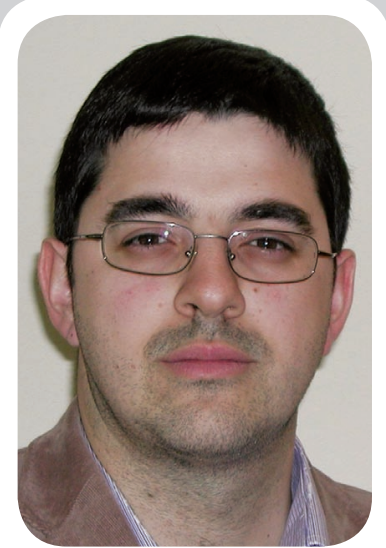

Xosé Pereira-Fariña es profesor titular del departamento de ciencias de la comunicación de la Universidad de Santiago de Compostela. Miembro del grupo de investigación Novos Medios, en la actualidad ocupa también el puesto de vicedecano en la Facultad de Ciencias de la Comunicación de la universidad compostelana.

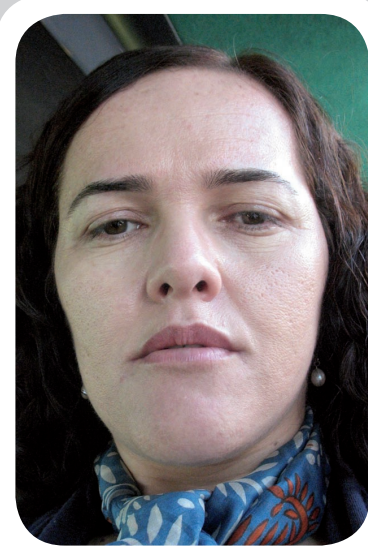

Suzana Barbosa es periodista y profesora del departamento de comunicação social de la Universidade Federal Fluminense (UFF) de Brasil. Es investigadora del grupo Centro de Estudos em Cibercultura, Meios Digitais e Espacialidades da Comunicação (UFF) y del Grupo de Pesquisa em Jornalismo On-line (UFBA).

Resumen: Con la irrupción de las nuevas tecnologías de la información y la comunicación (TIC), las rutinas de los profesionales que ejercen el periodismo se han visto afectadas: la inmediatez, una de las características esenciales que las TIC aportan al ejercicio del periodismo, lo ha convertido en un trabajo en el que adquieren gran importancia las bases de datos y las ventajas que estas aportan en el quehacer diario. Los periodistas manejan gran número de referencias relativas a bases de datos y cuentan con la posibilidad de acceder a una cantidad ingente de información desde internet. Además, las bases de datos se han convertido en estructuradoras del conocimiento, de los contenidos y en muchas ocasiones incluso en vertebradoras del discurso mediático.

Palabras clave: Bases de datos, Periodismo electrónico, Periodistas digitales, Nuevas herramientas, Información de calidad.

Title: Automation of databases: the potential of basic tools for a new kind of journalism

Abstract: The explosion of information and communication technologies (ICTs) has affected the work routines of professional journalists. Immediacy, one of the essential characteristics that the ICTs contribute to the practise of journalism, has turned the work of journalists into a race, with the databases contributing to the daily work. At present, journalists handle a great number of references relative to databases and rely on the possibility of access to an enormous quantity of information across the internet. In addition, databases have become a means of structuring the knowledge, content and in many cases even the infrastructure of media communication.

Keywords: Databases, Online media, Digital journalists, New tools, Qualit information.

López-García, Xosé; Toural-Bran, Carlos; Pereira-Fariña, Xosé; Barbosa, Suzana. “Automatización de las bases de datos: potencialidades de herramientas básicas para otro periodismo posible". El profesional de la información, 2009 , mayo-junio, v. 18, n. 3, pp. 308-315.

DOI: 10.3145/epi.2009.may.08

\section{El profesional del periodismo actual: el periodista digital}

EL PERIODISTA ACTUAL SE ENCUENTRA INMERSO en una estructura de comunicación producto de la profunda revolución que han experimentado los medios de comunicación en las últimas décadas de la mano de los avances tecnológicos aplicados al periodismo.

En pocos años, el profesional de la información de actualidad ha asistido a importantes cambios en 
el entorno, en las herramientas y en las propias características de los medios.

Los actores de la estructura actual, en fase de constantes transformaciones, se caracterizan por ser multimediales, interactivos y por estar interconectados. Así, los nuevos periodistas realizan su trabajo diario en entornos donde los discursos mediáticos se construyen mediante múltiples elementos (texto, vídeo, audio, fotografía...), combinados de forma que se constituyen en una narración con sentido. La llegada de internet supuso la aparición de una nueva fuente de información $\mathrm{y}$, al mismo tiempo, el nacimiento de un nuevo medio de comunicación, por lo que se convirtió desde el primer momento en "una herramienta de trabajo inevitable" para los periodistas (Meso-Ayerdi, 2002) y con ella nació un nuevo periodista, el llamado "periodista digital", profesional del periodismo digital ${ }^{1}$.

Sin pretender llegar al fondo de la cuestión en este trabajo, debemos mencionar el hecho de que con la irrupción de esta nueva figura, provocada en gran medida por la evolución de los formatos y la aparición de los nuevos medios de comunicación auspiciados por internet, también se ha hecho necesario replantear las enseñanzas periodísticas. Así, como indica Santiago Tejedor (2006: 237), el primer paso para esta reestructuración de la enseñanza con respecto al periodismo hecho en y para los medios digitales es reconocer la importancia que esta modalidad periodística tiene en nuestros días (Tejedor, 2007). Desde esta concepción del periodismo digital como un elemento relevante parte la necesidad de entender que "los profesionales de los cibermedios requieren una formación específica que les permita adquirir las competencias y habilidades propias del nuevo perfil de periodista que inaugura el periodismo on-line" (Tejedor, 2006: 237).
Mientras internet dio los pasos definitivos para quedarse, los periodistas vieron cómo los usuarios/ lectores de los medios para los que trabajaban asumían un rol activo e interactuaban con la macroestructura comunicativa, prioritariamente enviando comentarios, votando noticias, aportando textos propios así como imágenes o vídeos. De hecho, en la actualidad casi todo el que lo desee y esté capacitado puede producir información y distribuírla en internet valiéndose de las nuevas tecnologías digitales. Como consecuencia de estas actuaciones, a veces el periodista se encuentra ante una nueva realidad según la cual, en internet la información está dejando de ser jerarquizada por los periodistas, "dando lugar a jerarquías como lo más visto, lo más comentado o la simple jerarquización cronológica" (Peralta, 2008). Las distintas fórmulas de organización se convierten en una vía más de interactuación y diálogo entre los medios/periodistas y la audiencia.

Para algunos, esta situación conlleva la reinterpretación del rol del periodista. Hay quien opina que "el papel de vigilante se ve enriquecido con nuevas funciones relacionadas con el control de la calidad y la habilidad para elaborar una información completa y con criterio" (Rubio-Lacoba, 2007: 32). Weaver también trabaja con la idea de la capacitación del profesional como piedra de toque de su nuevo rol. Considera que será el periodista el más capacitado para decir lo que es importante y lo que no. En su opinión, a medida que haya más información rápidamente accesible

\section{"El periodista actual afronta como uno de los principales desafíos de los primeros años del siglo $X X I$ el uso eficiente de internet"}

desde los ordenadores y televisores domésticos conectados a internet, se hará necesaria la figura del periodista que nos ayude a dar sentido a esa cantidad ingente de información y a señalarnos lo que es verdaderamente relevante y cierto, y lo que no (Weaver, 1998: 223-224).

Otras voces señalan que la reinterpretación del rol del periodista en el contexto digital, dinamizada por la naturaleza abierta de internet, tiene mucho que ver con su relación con la audiencia (Heinonen, 1999: 48-49), participativa en esencia en el ámbito on line, hecho que provoca determinadas reacciones de los medios de comunicación y propicia la evolución del papel del periodista en el nuevo contexto (Paulussen; Domingo; Heinonen et al, 2008). Así, con las posibilidades de acceso inmediato a una cantidad ingente de información, el rol de filtro del periodista quedaría superado en la era digital y "los gatekeepers necesitarían nuevos trabajos" (Lasica, 1996: 20), ya que en esta época es la audiencia la encargada de decidir en cada momento a qué medio acudir y cómo tener acceso a una $\mathrm{u}$ otra información proveniente de infinidad de fuentes. Hay algunos autores que van más allá y ponen sobre la mesa lo que consideran el endiosamiento de la figura del periodista digital como profesional diferenciado del periodista tradicional (Almirón; Jarque, 2008).

La mejor manera de aproximarnos al perfil de un periodista digital $\mathrm{y}$, en concreto, de definir las funciones que realiza y sus rutinas diarias, es "determinar lo que hace" (MesoAyerdi, 2002). Las rutinas de los periodistas han cambiado ya que con la llegada de internet, "los periodistas se han convertido simultáneamente en emisores y receptores de la información que circula por la Red" (Sandoval-Martín, 2000). De hecho, se constata desde los años 90 la existencia de un grupo de rutinas profesionales que dife- 
rencian al periodista digital del periodista tradicional; a quien trabaja en una redacción convencional de quien trabaja en una redacción en red. Desde el campo profesional varios expertos se ocuparon desde los años 90 de establecer la diferenciación entre el periodista tradicional y el digital a la hora de definir sus rutinas de trabajo con respecto a las fuentes, las audiencias, los medios y los contenidos (Gil, 1999). Esta contraposición de rutinas entre el periodista tradicional y el conocido como periodista digital hace posible observar la diferenciación pro- fesional en cuanto a la práctica del periodismo, que se da con respecto a los cuatro ítems ya mencionados: fuentes, audiencias, medio y contenidos.

En la tabla 1, partiendo del texto de Quim Gil de 1999, se plantean algunos aspectos básicos recogidos a comienzos de la primera década de este siglo por Xosé López y María Luisa Otero (2007: 64) para establecer la diferencia entre ambos profesionales.

Del análisis comparativo recogido en la tabla 1 se concluye que las habilidades y responsabilidades surgidas en el contexto digital no implican la desaparición u omisión de las tareas del periodista tradicional (Heinonen, 1999: 51). Queda pues definido el perfil profesional del periodista digital como un "profesional en construcción" -evolución continua marcada por los procesos de cambio que se dan en el sector- que es el que actúa en el actual escenario. $Y$ es en este entorno donde debemos analizar la relación e interactuación entre las nuevas herramientas, los periodistas digitales y las bases de datos.

\begin{tabular}{|c|c|}
\hline FUENTES & $\begin{array}{l}\text { Periodista tradicional: asume que la información es un bien escaso; trabaja con fuentes propias y } \\
\text { lucha por mantenerlas como exclusivas; utiliza fuentes estables y ávidas (organismos con gabinetes } \\
\text { de comunicación que luchan por hacerse un hueco en las agendas de medios de comunicación). } \\
\text { Periodista digital: debe nadar en la abundancia de información y manejarse en la saturación de } \\
\text { datos; debe buscar fuentes fuera de la Red y hacer posible a sus audiencias el acceso a todas las } \\
\text { fuentes originales, de manera que puedan ampliar su conocimiento sobre el tema; debe jerarquizar } \\
\text { las fuentes y la información y sopesar en cada momento la importancia de cada fuente así como la } \\
\text { precisión de los datos. }\end{array}$ \\
\hline AUDIENCIAS & $\begin{array}{l}\text { Periodista tradicional: trabaja para un medio en concreto, bien sea prensa escrita, radio o te- } \\
\text { levisión; los contenidos son masivos, iguales para todo el público y para todas las condiciones de } \\
\text { consumo de la información; la producción de contenidos tiene costes fijos grandes y muy difíciles de } \\
\text { reducir; su contacto con los lectores es prácticamente nulo; trabaja con unas limitaciones técnicas } \\
\text { que una vez interiorizadas repite en cada jornada de trabajo/producto periodístico. } \\
\text { Periodista digital: su mentalidad debe ser trabajar y elaborar informaciones que puedan ser dis- } \\
\text { tribuidas por cualquier medio de comunicación (prensa escrita, radio, televisión o la Red); los conte- } \\
\text { nidos pueden ser personalizados, a gusto de cada consumidor; se elaboran diferentes versiones de } \\
\text { los contenidos dependiendo de factores como el ancho de banda, el tipo de navegador, la forma de } \\
\text { acceso (pda, teléfono móvil, ordenador...); producir contenidos básicos, de acceso gratuito o de bajo } \\
\text { coste es fácil, diferenciándolos de otras versiones de pago más completas; debe dedicar parte de su } \\
\text { tiempo y esfuerzo a interactuar con sus lectores, ya que éstos pueden ser también en algún momento } \\
\text { fuentes de información y generadores de corrientes de pensamiento. }\end{array}$ \\
\hline MEDIO & $\begin{array}{l}\text { Periodista tradicional: su identidad no es puesta en duda; trabaja con un pensamiento "monome- } \\
\text { dia", ya que sus productos tan sólo se distribuirán en un soporte que no le obliga a trabajar con la } \\
\text { hipertextualidad y es lineal, por lo que la información se distribuye estandarizada; su capacidad de } \\
\text { contextualización se limita al espacio físico asignado a cada texto; trabajan con la hora de cierre. } \\
\text { Periodista digital: debe tener en cuenta la perspectiva multimedia sobre la que se fundamenta su } \\
\text { trabajo y que marca que sus productos puedan ser distribuidos en varias plataformas, por lo que } \\
\text { debe tener en cuenta factores como el diseño de la interfaz y la arquitectura de la información; debe } \\
\text { tener en cuenta que la Red es hipertextual y multilineal; debe gestionar el caos y maremágnum de } \\
\text { la Red. "Internet se usa fundamentalmente para comprobar informaciones puntuales u obtener datos } \\
\text { concretos; para realizar búsquedas en profundidad, por el contrario, se tiende a complementar con } \\
\text { otros recursos de información, fundamentalmente el centro de documentación del medio" (Masip, } \\
\text { 2005: 569); debe contextualizar la información, ya que el almacenamiento digital de la información } \\
\text { permite a los lectores tener acceso a ella y debe sentirse bien informado. }\end{array}$ \\
\hline CONTENIDOS & $\begin{array}{l}\text { Periodista tradicional: sus contenidos se distribuyen en un continuo "ahora" que marca su vigen- } \\
\text { cia; el flujo informativo no es acumulativo y debe contextualizar cada noticia de manera pormenori- } \\
\text { zada e intensa para arropar informativamente los productos que distribuya a su audiencia; el formato } \\
\text { de las informaciones es cerrado. } \\
\text { Periodista digital: el flujo de la información en la Red es acumulativo, por lo que la publicación } \\
\text { de nueva información no implica suprimir la publicada con anterioridad, sino que se puede trabajar } \\
\text { a partir de ella; el formato de las informaciones es abierto, dejando posibilidad a la actualización y } \\
\text { ampliación; la vigencia de sus contenidos está marcada por la fecha y hora de la publicación. La Red } \\
\text { de redes está totalmente introducida en las rutinas diarias. }\end{array}$ \\
\hline
\end{tabular}




\section{Nuevas posibilidades que introducen las herramientas actuales}

Las tecnologías han marcado por tanto algunos aspectos del perfil del periodista digital. Con la llegada de las TIC los periodistas digitales han tenido que adaptarse a las nuevas herramientas profesionales que los medios de comunicación han ido incorporando a sus rutinas de trabajo y que hoy en día son imprescindibles para el ejercicio del periodismo.

Para los periodistas que habían trabajado toda la vida con máquinas de escribir como únicas herramientas -algo habitual hasta finales de los años 70 en la mayoría de los medios españoles-, la introducción en las últimas décadas del siglo XX de nuevos aparatos, aplicaciones informáticas y finalmente de internet en sus vidas resultó, en muchos casos, traumático. En algunos casos fue necesario un cambio de actitud - "dejar a un lado la tecnofobia, aquellos que se negaban a aprender los avances de la informática porque a primera vista resultaban complejos, costosos y que requerían una gran inversión de tiempo, debiendo replantear sus mitos y verdades" (Fuentes, 2000)- y un paso adelante a favor de la renovación y el aprovechamiento de las nuevas herramientas. En este sentido, fue importante que la mayoría de la profesión asumiese un lugar intermedio, que huyó de la tecnofobia al mismo tiempo que se alejó de la euforia tecnoglobalista (LópezGarcía, 2001).

El periodista actual ha tenido que aprender a trabajar primero con la informática y más tarde con internet como una de sus herramientas de referencia. Sin duda, los nuevos periodistas han visto cómo las rutinas tradicionales han evolucionado de la mano de las aplicaciones que las nuevas tecnologías han proporcionado gracias a la Red. En esta renovación y avance han tenido un destacado papel los profesionales más jóvenes incorporados a los medios de comunicación españoles a partir de finales de los años ochenta y comienzos de los noventa.

\section{"El desarrollo continuo de bases de datos es un aspecto crítico para el periodismo y para los medios en el futuro"}

\subsection{Periodismo digital en bases de datos}

El periodista digital, que pronto se adentró en el nuevo escenario tecnológico, no sólo caminó con internet, sino que también lo hizo con las bases de datos. Fueron precisamente las funciones de las bases de datos las que abrieron nuevos caminos al periodismo digital y hoy lo sitúan en un escenario propicio para hacer realidad otro periodismo posible.

Estas posibilidades de las bases de datos se refieren a cimentar la estructuración y documentación de las informaciones, la dinamización, contextualización, la creación de nuevos modelos narrativos, así como la diversidad temática y patrones nuevos para la visualización de los contenidos periodísticos. Es por ello que autores como Elías Machado (2006), Rich Gordon (2007), Antonio Fidalgo (2007b) abogan por la opción que denomina a esta práctica "periodismo digital en base de datos". Es decir, mantienen la denominación de periodismo digital y lo relacionan con las bases de datos como "compañeros inseparables".

Mientras que Fidalgo entiende las bases de datos como el elemento diferenciador entre el periodismo digital y las modalidades tradicionales, Machado va más allá y les da la función de formato y espacio para la composición de las narrativas multimedia. Destaca este autor que, al volverse mucho más racionalizadas y flexibles las relaciones del producto periodístico digital ${ }^{2} \mathrm{y}$ la propia producción de dicho producto, "as bases de dados permitem a reestruturaçao destas relaçoes no jornalismo, podendo transformar por completo as funçoes tanto dos jornalistas, quanto dos usuários destas publicaçoes" (Machado, 2006: 8). Para Gordon (2007), las bases de datos presentan nuevos modos de participación a las audiencias y nuevas posibilidades de ofrecer el periodismo de calidad que la sociedad necesita y valora. Así, el desarrollo continuo de bases de datos se asienta como un aspecto crítico para el periodismo y para los medios en el futuro.

De acuerdo con la pespectiva de Barbosa (2007a), ese protagonismo ejercido por las bases de datos en el campo del periodismo las coloca como elementos constituyentes de un paradigma: el denominado $\mathrm{Mo}$ delo Jornalismo Digital em Bases de Dados (JDBD), descrito como "que tem as bases de dados como definidoras da estrutura e da organizaçao, bem como da apresentaçao dos conteúdos de natureza jornalística, de acordo com funcionalidades e categorias específicas, que vao permitir a criaçao, a manutençao, a atualizaçao, a disponibilizaçao e a circulaçao de produtos jornalísticos digitais dinâmicos" (Barbosa, 2007a: 218).

\section{"La contextualización es un punto esencial en la producción del mensaje periodístico actual de calidad"}

Entre estas funciones están: orientar y apoyar el proceso de investigación, recogida y contextua- 
lización de los contenidos; regular el sistema de categorización y cualificación de las distintas fuentes periodísticas indicando su relevancia; conformar patrones nuevos para la construcción de las piezas informativas; gestionar el flujo de información y el conocimiento en las redacciones; generar información para las distintas plataformas; apoyar acciones de interacción que impliquen a usuarios y profesionales mediante el contenido informativo y de entretenimiento, entre otras. Las categorías complementan las propiedades del Modelo JDBD (dinamismo; automatización, flexibilidad, interrelacionamiento/hipervínculos; densidad informativa; diversidad temática; visualización y convergencia).

Las aportaciones de estos autores favorecen la ampliación del significado de las bases de datos en el campo del periodismo, alterando su status de carácter meramente auxiliar hasta el momento, para atribuirles un estatuto propio.

\subsection{Periodistas digitales $y$ bases de datos}

El camino, de acuerdo con los citados puntos de vista, está en aprovechar todas las posibilidades del periodismo digital en bases de datos. Hoy por hoy, las infinitas relaciones existentes entre las diferentes áreas que componen la sociedad-político, económico, social, cultural...-, tanto verticales como horizontales, intra y extrasectorialmente, hacen que lo más importante de un hecho sea su ubicación en el universo de la realidad y que el periodista lo revele con perspectiva, es decir, situándolo en el entramado relacional de la sociedad. El empleo de las bases de datos permitirá, además de contextualizar, "descubrir - gracias a la comparación de hechos- falacias, sofismas y todo tipo de información y antecedentes que serán beneficiosos para todos" (Fuentes, 2000). Las bases de datos asumen, en este contexto, el rol de memoria colectiva (Ma- chado, 2006: 25-26) y se sitúan como eje del proceso creativo en la era de los ordenadores (Manovich, 2001: 200).

La necesidad de contextualizar las informaciones -bien sea desde internet, mediante bases de datos propias o bases de datos de lo publicado- a causa de la realidad compleja en que la sociedad se desenvuelve, entronca directamente con el concepto de resolução semântica (de ahora en adelante "resolución semántica") que define António Fidalgo y que pone de manifiesto las importantes contribuciones que las bases de datos aportan al periodismo. Para este autor, "tal como uma imagem digital aumenta a sua qualidade com o aumento da resolução gráfica, ou seja, como o número de pixels por centímetro quadrado, também a pluralidade e a diversidade das noticias online sobre um evento aumenta a informaçao sobre o mesmo, aumentando a resolução semântica” (Fidalgo, 2007: 101).

El concepto de resolución semántica favorece, entonces, la contextualización de las noticias permitiendo al usuario acceder a datos que le ayudarán a entender determinada situación o hecho, ventaja enfatizada por el periodismo digital que se vale de las bases de datos. Como se observa, Fidalgo desenvuelve el concepto especialmente para el periodismo electrónico ya que afirma que "a resolução semântica não se resume apenas a elementos escritos, mas incorpora também elementos sonoros e visuais" (Fidalgo, 2007: 105) que contribuyen, en todo caso, a aumentar la precisión de una noticia o información.

En este punto, Suzana Barbosa, (2007b: 132) destaca que la mayor función operativa de las bases de datos es la de la estructuración de la información, ya que para el periodismo digital las bases de datos son elementos definitorios de la estructura y la organización de las informaciones, además de su pre- sentación formal, dando respuestas a la preocupación por la estructuración de la información y su arquitectura mostrada por Fidalgo. Para Barbosa (2007b: 130), "as funcionalidades das bases de dados para o jornalismo digital são percebidas tanto quanto à gestão interna dos produtos como em relação às mudanças no âmbito da estruturação das informações, da configuração e da apresentação da notícia [...], assim como da recuperação das informações".

\section{Modelos de trabajo en medios actuales}

A partir de las explicaciones de los investigadores citadas en este trabajo y de las tesis expuestas, es posible afirmar que las bases de datos han estado en el centro de los grandes cambios que han experimentado los medios de comunicación en todo el mundo. Si consideramos los procesos de convergencia periodística, verificamos también que las bases de datos son agentes centrales para estructurar y fortalecer redacciones cada vez más integradas y que operan siguiendo la lógica de ese modelo de periodismo convergente. De esta forma, en muchos casos, las bases de datos constituyen el eje estratégico de los grupos y empresas informativas que operan de modo integrado.

Uno de los principales ejemplos es el caso de Ganett.co -propietaria, entre otros periódicos, de USA Today-, donde el concepto de Information Center o Centro de información ha sustituido a la redacción tradicional, colocando a las bases de datos como agentes fundamentales de su nueva estructura organizacional en los procesos de investigación, producción, presentación y distribución de la información. En el concepto de Information Center, el data desk es uno de los pilares de la compañía para abordar la noticia (Gordon, 2007).

http://www.gannet.com 
En Associated Press (AP) un sofisticado sistema de bases de datos combina las referencias a noticias, reportajes, fotografías, gráficos, material de audio y vídeo. Cualquiera de estos elementos puede ser consultado tanto por los profesionales de la agencia como por todos sus clientes mediante un buscador protegido por contraseña. Los periodistas están organizados y dispuestos alrededor de un tipo de medio según su soporte y utilizan un flujo de contenidos de una base de datos única para la producción y la distribución.

\section{http://www.associatedpress.com}

En el caso de España, en medios como El país.com ${ }^{3}$, La voz de Galicia y El correo gallego las bases de datos desempeñan igualmente un papel central, pues en ellas recae el peso de los sistemas de publicación y gestión de contenidos que permiten la integración editorial de los distintos medios pertenecientes a los respectivos grupos. De esta manera, los grupos pueden optimizar la gestión de los recursos, reforzar acciones conjuntas, adaptar contenidos para distribuirlos desde las distintas plataformas, intensificar la complementación periodística con mayor coherencia editorial y asegurar la automatización de muchos procesos favoreciendo de este modo, que los periodistas puedan concentrarse en el trabajo intelectual. Otros ejemplos en España son la Agéncia Catalana de Noticies, ACN, y la Corporació Catalana de Mitjans Audiovisuals, CCMA, emisora pública catalana. En ambos casos trabajan con la generación y distribución de contenidos mediante bases de datos on-line $(A C N)$ y bases de datos comunes para TV e internet ( $C C R T V)$.

\section{http://www.elpais.com}

http://www.lavozdegalicia.es http://www.elcorreogallego.es http://www.intracatalonia.com http://www.ccrtv.es
Un último ejemplo a destacar es el grupo colombiano El tiempo, en el que la estrategia de integración de redacciones ha definido un nuevo modelo de trabajo: los periodistas han sido divididos en dos grandes grupos de producción, uno de ellos dedicado a los diferentes productos y marcas de El Tiempo, mientras que en el otro colectivo los periodistas trabajan en grupos temáticos (según diferentes áreas de especialización) para generar contenidos en diferentes formatos, alimentando una base de datos común disponible para cualquier producto informativo del grupo, tejiendo una especie de agencia informativa interna.

\section{"Las bases de datos han estado en el centro de los grandes cambios que han experimentado los medios de comunicación en todo el mundo"}

\section{Conclusiones}

El paso de la sociedad postindustrial a la sociedad de la información y el conocimiento ha supuesto grandes cambios para el periodismo. Las nuevas tecnologías han permitido la aparición de internet y con la Red de Redes se han visto alterados muchos de los estamentos periodísticos tradicionales. El surgimiento del periodismo electrónico no es más que la punta del iceberg de toda una serie de cambios que el sistema productivo mediático ha experimentado en los últimos veinticinco años.

A raíz de las mudanzas producidas, se ha constatado que hoy el empleo de las bases de datos por parte del periodista digital permite contextualizar ya que las bases de datos asumen el papel de memoria colectiva y se constituyen en columna vertebral para los procesos creativos posibles en el periodismo. Una cuestión distinta es si en la práctica profesional se aprovechan todas sus potencialidades -los datos de los cibermedios analizados indican que en la mayoría de los productos se aprovechan poco-.

Lo que se deduce de los modelos de trabajo en los medios actuales es que las bases de datos contribuyen a que el periodista realice su trabajo con la máxima precisión y rapidez -condición esta última impuesta por la inmediatez característica de los sistemas de comunicación propios de nuestra época-. Estas bases permiten al periodista recuperar información y contextualizar las noticias. Como hemos explicado, la contextualización es un punto esencial en la producción del mensaje periodístico porque, sin la necesaria ubicación del hecho en un contexto social, el lector/usuario no será capaz de elaborar un pensamiento crítico con respecto al tema.

Las bases de datos han estado en el centro de algunos de los grandes cambios que han vivido los medios de comunicación en todo el mundo. Con la digitalización de los elementos que conforman nuestra cultura (textos, audio, vídeo, fotografías, ect.) y su disponibilidad en internet, se contribuyó a extender el uso de los sistemas de documentación e información entre los periodistas y a que estos reconozcan su relevancia a la hora de producir información. De hecho, en varios medios las bases de datos son agentes centrales para estructurar y fortalecer redacciones cada vez más integradas.

Las bases de datos han cimentado su relevancia creciente en base a la posibilidad de funcionar como formato y como espacio óptimos para la composición de narrativas multimedia. Además, valiéndose de las múltiples opciones de interactuación que pueden ofrecer a las audiencias $-\mathrm{y}$ concretamente a las audiencias más activas-, las bases de datos se han configurado como 
un elemento de relevancia capital en la configuración del panorama mediático actual, tal y como demuestran casos concretos como los de El país.com, la CCMA, la $A C N$, El correo Gallego, La voz de Galicia o Associated Press.

El papel de las bases de datos cobra mayor relevancia si es observado desde la perspectiva del panorama mediático actual, donde la inmensa mayoría de los grupos de comunicación están inmersos en procesos de convergencia. En este contexto, observamos cómo el factor común de las bases de datos se sitúa en el epicentro de estos fenómenos, no como causa, sino com solución en muchos casos que los grupos adoptan para estructurar sus nuevas redacciones y el trabajo de las mismas, tal y como ilustran los casos de los grupos $G a$ nett.co y El tiempo.

En definitiva, el periodismo actual mantiene una estrecha relación con las bases de datos y los sistemas de almacenamiento de información, al margen del aprovechamiento que se haga de esas potencialidades. El periodismo se vale de las ventajas que supone tener información indexada a la hora de contextualizar las informaciones. La inmediatez de la que dotan las nuevas tecnologías de la información y la comunicación (TIC) a las comunicaciones actuales es un difícil escollo para la labor periodística, que requiere de cierto tiempo de reflexión y búsqueda de contexto en diversas fuentes documentales, pero que las rutinas profesionales y el trabajo en los medios pocas veces favorecen. Las bases de datos, mediante sus gestores de contenido y sus mecanismos de recuperación de información, permiten al periodista trabajar con acceso inmediato a miles de ficheros, informaciones, imágenes y material audiovisual con el que vestir sus informaciones y presentar a los usuarios productos de calidad que contribuyen a crear una visión crítica en la sociedad sobre los hechos y acontecimientos que tratan.

\section{Notas}

1. Aunque en este trabajo empleamos el término "periodismo digital", debemos indicar que hay autores que emplean otras denominaciones. Entre otros podemos citar "ciberperiodismo" (Salaverría, 2005), webjornalismo (Canavilhas, 2001; Mielniczuk, 2003), "periodismo online" (Hall, 2001) o "periodismo contextualizado" (Pavlik, 2005), mientras que Elías Machado (2006), Suzana Barbosa (2007a, 2007b), Rich Gordon (2007) y Antonio Fidalgo (2007b) optan por "periodismo digital en bases de datos". Si bien en otros contextos hemos empleado el término "ciberperiodismo", para este trabajo nos parece más oportuno y concreto -por el objeto del artículo- hablar en general de "periodista digital" y, en perfiles específicos, de "periodistas digitales que trabajan con bases de datos".

2. "La flexibilidad de los medios online permite organizar las informaciones de acuerdo con las diversas estructuras hipertextuales. Cada información, de acuerdo con sus peculiaridades y los elementos multimedia disponibles, exige una estructura propia." (Salaverría, 2005: 108).

3. Este es uno de los medios que posee uno de los más consolidados sistemas de documentación. El robusto sistema de bases de datos está conceptualmente apoyado en un marco documental normalizado de acuerdo con el formato International Press Telecommunications Council (IPTC).

4. Los datos puntuales para esta afirmación se extraen de la investigación realizada en dos proyectos coordinados y financiados en convocatoria pública por el gobierno español desde el Ministerio de Ciencia y Tecnología como es el caso de El impacto de internet en los medios de comunicación en España-Radio (referencia BSO20020406-C04-02), y desde el Ministerio de Ciencia e Innovación en el caso del proyecto Convergencia digital en los medios de comunicación-Medios" (referencia SEJ2006-14828-C06-03) dirigidos por Xosé López García. Los datos obtenidos y las conclusiones extraídas de estos proyectos se confirman también en el ámbito gallego, como se está comprobando con la realización de un nuevo proyecto denominado Tendencias na converxencia dos medios de comunicación en Galicia 2007-2010 (referencia PGIDIT07-PXIB212149PR), financiado por la Xunta de Galicia desde la Consellería de Innovación e Industria.

\section{Bibliografía}

Almirón, N.; Jarque, J. M. El mito digital. Discurso hegemónico sobre internet y periodismo. Barcelona: Anthropos, 2008.

Barbosa, S. "Jornalismo Digital em Base de Dados (JDBD): Um paradigma para produtos jornalísticos digitais dinâmicos". (Tese de Doutorado). FACOM/UFBA, Salvador: 2007a.

http://www.facom.ufba.br/jol/producao_teses. htm

Barbosa, S. "Sistematizando conceitos e características sobre o jornalismo digital em base de dados". En Barbosa, S. Jornalismo digital de tereceira geração. Covilhã: Livros LABCOM, 2007b.

Canavilhas, J. "Webjornalismo: consideraçoes gerais sobre jornalismo na web". Bocc, 2001. http://www.bocc.ubi.pt/pag/_texto. php3?html2=canavilhas-joao-webjornal.html
Codina, L. "Documentación en los medios de comunicación: la función de la información documental en la producción de la noticia". lluiscodina.com, 2002, agosto.

http://www.lluiscodina.com/articulos/docper.doc

Fidalgo, A. Data mining e um novo jornalismo de investigação. En BARBOSA, S. Jornalismo digital de tereceira geração. Covilhã: Livros LABCOM, 2007a.

Fidalgo, A. A resolução semântica no jornalismo online. En Barbosa, S. Jornalismo digital de tereceira geração. Covilhã: Livros LABCOM, $2007 \mathrm{~b}$

Fuentes, A. D. "Nuevas reglas de juego en el periodismo". Sala de Prensa, 2000, septiembre, n. 23.

http://www.saladeprensa.org/art153.htm

Fuentes, M. E. Documentación y periodismo. Pamplona: Eunsa, 1997.

Galdón-López, G. Principios operativos de la documentación periodística. Madrid: Dossat, 1989.

Gil, Q. "Diseñando el periodista digital". Sala de Prensa, 1999, noviembre, n. 13. http://saladeprensa.org/art89.htm

Gordon, R. "Data as journalism, journalism as data”. Readership Institute, año 2007. http://www.readership.org/default.asp

Hall, J. Oline journalism. A critical pimer. Londres: Pluto Press, 2001.

Heinonen, A. Journalism in the age of the net. Changing society, changing profession. Tampere: Tampere University Press, 1999.

Lasica, J. D. "Net Gain. Journalism's challenges in an interactive age". American journalism review, 1996, v. 20, n. 2

http://www.ajr.org/article.asp?id=2217

López-García, X. "Nuevos soportes para un periodismo necesitado de reflexión crítica". Sala de Prensa, 2001, diciembre, n. 38

http://www.saladeprensa.org/art296.htm

López-García, X.; Otero, M. L. "El nuevo profesional y las nuevas profesiones". En García Jiménez, A.; Rupérez Rubio, P. Aproximaciones al periodismo digital. Madrid: Universidad Rey Juan Carlos, 2007.

Machado, E. O jornalismo digital em base de dados. Florianópolis: Calandra, 2006.

Manovich, L. The language of new media. Cambridge, Massachussets: MIT Press, 2001.

Masip, P. "Rutinas periodísticas e internet en la información diaria". Trípodos Extra. La utopia digital en els mitjans de comunicació: dels discursos als fets. Un balanç, 2005, v. 2, n. 4.

Meso-Ayerdi, K. "Un nuevo tipo de profesional llama a las puertas del periodismo: el periodista digital". Revista latina de comunicación social, 2002, junio, n. 51.

http://www.ull.es/publicaciones/latina/ 2002mesojunio5103.htm

Mielniczuk, L. "Jornalismo na Web: uma contribuição para o estudo do formato da notícia na escrita hipertextual". (Tese de Doutorado). FACOM/UFBA, Salvador. Scribd, 2003

http://www.scribd.com/doc/12769270/Jornalismo-na-web-uma-contribuicao-para-o-estudodo-formato-da-noticia-na-escrita-hipertextual 
Paulussen, S.; Domingo, D.; Heinonen, A. et al. "Citizen participation in online news media. An overview of current developments in four European countries and the United States". En Quandt, T.; Schweiger, W. Journalismus online - Partizipation oder profession?. VS Verlag für Sozialwissenschaften, 2008

Pavlik, J. El periodismo y los nuevos medios de comunicación. Barcelona: Paidós Comunicación, 2005

Peralta, D. "Internet y la transformación del periodismo". Sala de Prensa, 2008, agosto, n. 106. http://www.saladeprensa.org/art766.htm

Rubio Lacoba, M. Documentación informativa en el periodismo digital. Madrid: Editorial Síntesis, 2007.
Salaverría, R. Redacción periodística en internet. Pamplona: EUNSA, 2005.

Sandoval Martín, M. T. "Los periodistas en el entorno digital: hacia el periodista multimedia". Sala de Prensa, 2000, noviembre, n. 25 http://saladeprensa.org/art164.htm

Tejedor, S. La enseñanza del ciberperiodismo. Sevilla: Comunicación Social. Ediciones y $\mathrm{Pu}$ blicaciones, 2007

Tejedor, S. "La enseñanza del ciberperiodismo: hacia una transversalidad mixta". ZER. Revista de estudios de comunicación, 2006, n. 21.

Weaver, D. "Periodismo y nuevas tecnologías: perfiles de los periodistas del siglo XXI". Cuadernos de información y comunicación, 1998, n. 4.
Xosé López-García,Carlos TouralBran, Xosé Pereira-Fariña, Grupo Novos Medios, Universidade de Santiago de Compostela.

jose.lopez.garcia@usc.es carlostoural@gmail.com xose.pereira@usc.es

Suzana Barbosa, Universidade Federal Fluminense, UFF. Rio de Janeiro.

suzanabarbosa@vm.uff.br

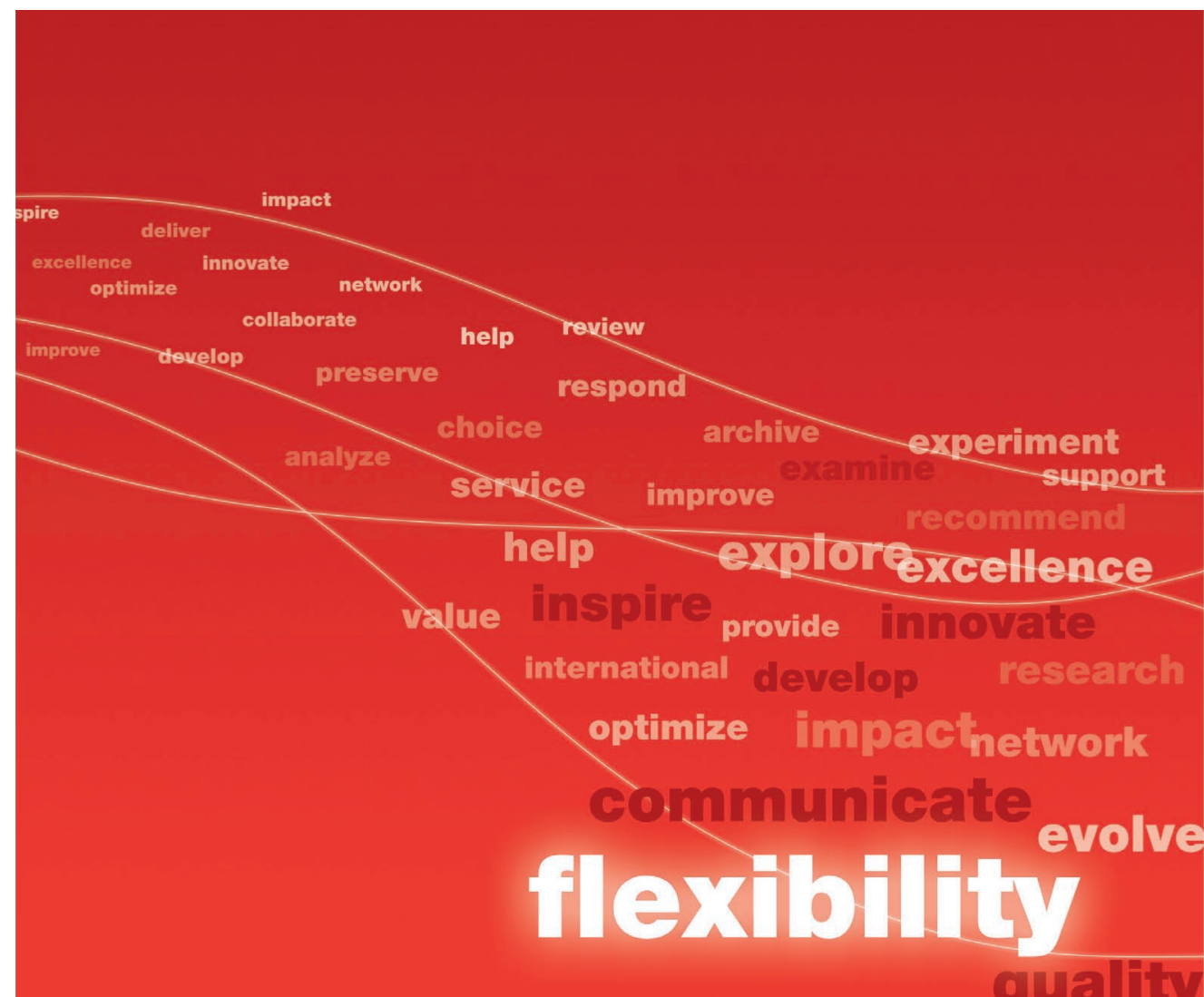

Licencia de acceso es el modelo flexible de NPG

que le permite seleccionar las subscripciones más importantes para su institución. Elige entre publicaciones de alta calidad de Nature Publishing Group y Palgrave Macmillan para crear una licencia que se ajuste a sus requerimientos y a las necesidades de sus usuarios.

Sin paquetes. Total flexibilidad. Su elección.

Para más información, diríjase a www.nature.com/libraries 